\title{
The performance of deterministic and stochastic interest rate risk measures:
}

\section{Another Question of Dimensions?}

\section{Luís Oliveira · João Pedro Vidal Nunes · Luís Malcato}

Received: 15 July 2013 / Accepted: 17 September 2014 / Published online: 9 October 2014 (C) ISEG 2014

\begin{abstract}
The efficiency of traditional and stochastic interest rate risk measures is compared under one-, two-, and three-factor no-arbitrage Gauss-Markov term structure models, and for different immunization periods. The empirical analysis, run on the German Treasury bond market from January 2000 to December 2010, suggests that: i) Stochastic interest rate risk measures provide better portfolio immunization than the Fisher-Weil duration; and ii) The superiority of the stochastic risk measures is more evident for multi-factor models and for longer investment horizons. These findings are supported by a first-order stochastic dominance analysis, and are robust against yield curve estimation errors.
\end{abstract}

Keywords Interest rate risk - Asset-liability management - Immunization strategies ' Stochastic duration ' Stochastic dominance

JEL Classifications $\mathrm{G} 11 \cdot \mathrm{G} 12 \cdot \mathrm{G} 20 \cdot \mathrm{C} 15 \cdot \mathrm{E} 43$

Financial support by FCT's grant number PTDC/EGE-ECO/099255/2008 is gratefully acknowledged.

L. Oliveira · J. P. Vidal Nunes

BRU-UNIDE and ISCTE-IUL Business School, ISCTE-IUL, Edifício II, Av. Prof. Aníbal

Bettencourt, 1600-189 Lisboa, Portugal

e-mail: joao.nunes@iscte.pt

L. Oliveira

e-mail: luis.oliveira@iscte.pt

Luís Malcato

APS-Portuguese Association of Insurers, Rua Rodrigo da Fonseca 41, 1250-190 Lisboa, Portugal e-mail:1malcato@apseguradores.pt 